\title{
Is the cultural context of MMR rejection a key to an effective public health discourse?
}

\author{
J.A. Cassell ${ }^{a, *}$, M. Leach ${ }^{b}$, M.S. Poltorak ${ }^{c}$, C.H. Mercer ${ }^{a}$, A. Iversen ${ }^{d}$, \\ J.R. Fairhead ${ }^{c}$
}
${ }^{a}$ Department of Primary Care and Population Sciences, Royal Free and University College Medical School, Rowland Hill Street, London NW2 2PF, UK
${ }^{\mathrm{b}}$ Institute of Development Studies, University of Sussex, Falmer, Brighton, UK
'Department of Anthropology, University of Sussex, Falmer, Brighton, UK
${ }^{\mathrm{d}}$ Surrey and Sussex Health Protection Unit, Health Protection Agency, UK

Received 9 August 2005; received in revised form 4 February 2006; accepted 2 March 2006 Available online 7 July 2006

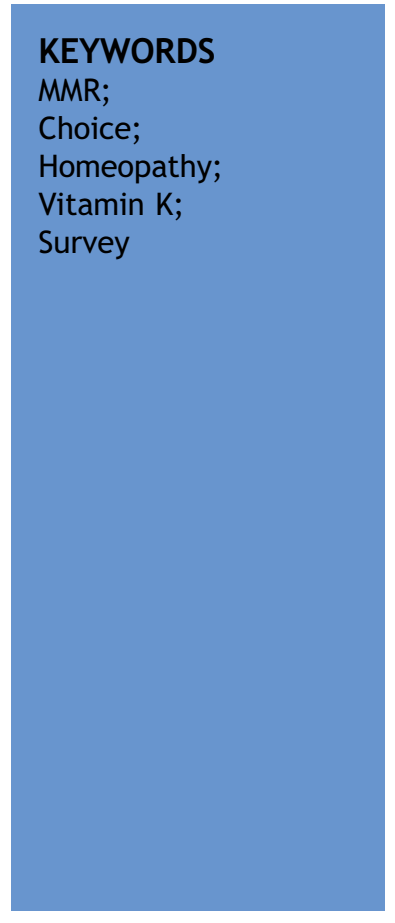

\begin{abstract}
Summary Objectives: (1) To explore the social and cultural influences, and health beliefs associated with low uptake of MMR (measles, mumps and rubella vaccine). (2) To describe and explore the prevalence of health beliefs associated with noncompliance with MMR, with a view to improving the personal relevance and impact of information for parents, in the context of persisting low uptake following public controversy.

Methods: We undertook a survey of mothers' experiences of and attitudes to the MMR, developed through ethnographic study, which was linked to maternal and child information on the Child Health Database in Brighton, England.

Results: Mothers interpret MMR risk through concepts of child health embedded in family health history, with a majority both of compliers and non-compliers holding that each child's immune system is unique. Cultural 'risk factors' for non-compliance relate strongly to the use of complementary healthcare, such as homeopathy, with evidence that rejection of vitamin $\mathrm{K}$ is associated with MMR non-compliance. Forty per cent, both of compliers and non-compliers, did not consider the possible benefits to other children of MMR.

Conclusions: These findings have paradoxical and challenging consequences for the promotion of immunization in the policy context of increasing emphasis on healthy choices. They demonstrate the need for immunization information that acknowledges and addresses lay concepts of immunity.

(c) 2006 The Royal Institute of Public Health. Published by Elsevier Ltd. All rights reserved.
\end{abstract}

\footnotetext{
*Corresponding author. Tel.: +440207472 6748; fax: +4402074319114.

E-mail address: j.cassell@pcps.ucl.ac.uk (J.A. Cassell).
} 


\section{Introduction}

Public debate about the safety of the measles, mumps and rubella (MMR) vaccine has continued in the UK since the publication of controversial data ${ }^{1-5}$ that raised concerns about adverse effects, but which has not been supported by epidemiological studies. ${ }^{6-8}$ Low rates of uptake, particularly of the first MMR dose at 13 months, followed. Governmental publicity campaigns aimed at reassuring parents continue, and are accompanied by surveys of maternal attitudes. ${ }^{9}$

The long duration of this downturn in MMR immunization rates, and the fact that it is not associated with economic deprivation (a risk factor for low uptake of immunization generally), ${ }^{9,10}$ have given rise to the hypothesis that MMR refusal may reflect a wider and developing distrust of government and its associated health institutions. This could have significance for a range of public health programmes, particularly immunization.

The need to combine qualitative and quantitative research methods in this field has been established. ${ }^{11}$ In this study, we present data from a survey whose content was based on ethnographic study in a population with low rates of MMR uptake. $^{12}$ The survey drew on parental narratives about MMR decision-making and explored the relevance in a wider population of a range of social and cultural issues raised by parents in interviews and focus groups.

\section{Materials and methods}

\section{Population and sampling}

The sampling frame for our study consisted of all children aged 15-24 months listed on the Child Health Dataset held by South Downs Health NHS (National Health Service) Trust as resident in the catchment area of Brighton and Hove City PCT (Primary Care Trust), in early March 2004. Brighton and Hove is a coastal city, where uptake of MMR immunization as recorded on the Child Health Dataset is low with $69 \%$ recorded as having had MMR by age 2 in the financial year 2003-2004, by contrast with $86 \%$ in England as a whole. ${ }^{13}$ Children were categorized into those who had and had not had an MMR immunization recorded, and of the 1800 children eligible, a sample of 1000 MMR uptakers and non-uptakers in a ratio of $1: 1$ was randomly drawn, using the statistical program STATA $^{\text {TM }}$ Version 8 . All the 135 registered children who had had no vaccination events recorded were also sampled.
A postal questionnaire addressed to the mother or guardian of each child was sent in March 2004. This contained a questionnaire for the mother, and also one to be passed where possible to the father of the child (not reported here). A follow-up letter with a second questionnaire was sent after 3-4 weeks to non-responders, with the exception of children who had had no vaccinations recorded, due to late receipt of the data needed for sampling.

\section{Questionnaire design}

The questionnaire was developed following 6 months of ethnographic study, reported elsewhere. ${ }^{12}$ It was designed to explore hypotheses about emerging MMR concerns, and their relation with maternal demographic and compliance characteristics, in a representative population sample. The content and design of the questionnaire was developed by the multidisciplinary team of authors together with an advisory group, which included anthropologists, epidemiologists, public health specialists, community nursing specialists, vaccine damage activists and national policy makers.

The questionnaire explored the following issues: rank of child within the family; sources of information on parenting and immunizations; early health of the child (including its birth); views on the risks associated with measles and the MMR; interactions with healthcare professionals and others in relation to MMR; the process of decision-making, including attitudes to public bodies and governments as sources of advice and influence. In addition, a range of specific statements made by Brighton parents as part of the ethnographic study was offered for agreement or disagreement.

\section{Data linkage}

Completed questionnaires were linked with children's data as recorded on the Child Health Database, from which additional information was derived relating to: gestational age, number of previous live births, age of mother at child's birth and immunizations given within the NHS. After linkage, the dataset was anonymized.

\section{Approach to analysis}

Following construction of maternal and child demographic and health variables, a response rate was calculated for responders, non-responders and those who had no vaccinations recorded. Responses to the questionnaires were used to classify mothers 
into self-reported 'compliant' and 'non-compliant groups' of which further details are given below, and characteristics of responders and non-responders described. Associations between responses to the questionnaire and compliance were then explored using the $\chi^{2}$ test. Finally a multivariate analysis was undertaken, in which odds ratios (OR, adjusted and unadjusted) for compliance in relation to measurable objective variables of potential use in predicting non-compliance were calculated.

\section{Ethical review and research governance}

The study was approved by the Brighton Local Research Ethics Committee, and appropriate research permissions given by South Downs Health NHS Trust and Brighton and Hove City PCT. Apart from mailing lists, all person-identifiable data were handled by JC on secure NHS servers with appropriate permissions. Anonymized data have been lodged at the ESRC National Data Archive (http:// www.data-archive.ac.uk).

\section{Results}

\section{Response rate}

Of 1135 mothers' questionnaires, 452 (39.8\%) were returned, with $45 \%$ response from those for whom MMR was recorded, $37.4 \%$ from those having some vaccinations but not MMR recorded, and $29.6 \%$ response from mothers of children for whom no vaccinations were recorded on the Child Health Database ('non-vaccinators'). Table 1 describes and compares the characteristics of responders and non-responders. The 40 non-vaccinator mothers had a similar age distribution to others, but slightly more previous live births (1.0 compared to 0.8 , $P=0.009$ ), and more of their children were male (60\% compared to $49.9 \%, P=0.081$ ).

\section{Vaccination decisions}

Table 2 summarizes the relationship between vaccine decision and demographic characteristics. There was no association between graduate status $(P=0.14)$ or age at the birth of this child $(P=0.12)$ and the decision whether to have MMR at the recommended time. However, mothers were more likely to accept MMR for a first child than for subsequent children $(61.1 \% \vee 53.6 \%, P=0.002)$.

Of all mothers, $17.5 \%$ reported that they had chosen 'single jabs' (i.e. separate measles, mumps and rubella antigens, available only privately or overseas). None of these children were reported as having had MMR in the Child Health Dataset. These children were less likely to be firstborn $(P=0.02)$, while there was no difference in maternal age or graduate status. Of all respondents, $10.6 \%$ reported a decision to delay the MMR.

Mothers were classified into the categories of 'compliant' or 'non-compliant' for the analysis on

\begin{tabular}{|c|c|c|c|c|}
\hline & $\begin{array}{l}\text { Responder } \\
(N=452) n(\%)\end{array}$ & $\begin{array}{l}\text { Non-responder } \\
(N=683) n(\%)\end{array}$ & Base $(N=1153)$ & $\begin{array}{l}P \text { value for } \\
\text { difference }\end{array}$ \\
\hline \multicolumn{5}{|l|}{ Age at birth of this child: } \\
\hline$<18$ & $1(0.2)$ & $13(2.0)$ & & \\
\hline $18-20$ & $5(1.1)$ & $45(7.0)$ & & \\
\hline $21-24$ & $28(6.4)$ & $71(11.1)$ & & \\
\hline $25-34$ & $233(53.2)$ & $315(49.1)$ & & \\
\hline $35+$ & $171(39.0)$ & 197 (30.7) & $1079(56)$ & $<0.001$ \\
\hline \multicolumn{5}{|l|}{$\begin{array}{l}\text { MMR before } 15 \text { months according } \\
\text { to child health records: }\end{array}$} \\
\hline Yes, had MMR & $225(49.8)$ & $275(40.3)$ & & \\
\hline No, but had some other & $187(41.4)$ & $313(45.8)$ & & \\
\hline \multicolumn{5}{|l|}{ vaccinations } \\
\hline No vaccinations recorded & $40(8.9)$ & $95(13.9)$ & $1135(0)$ & 0.002 \\
\hline \multicolumn{5}{|l|}{ Born 36 weeks or less gestation: } \\
\hline$\leqslant 36$ weeks & $32(7.3)$ & $45(7.0)$ & & \\
\hline$>36$ weeks & $406(92.7)$ & $594(93.0)$ & $1077(58)$ & 0.869 \\
\hline \multicolumn{5}{|l|}{ Sex (this child): } \\
\hline Male & $237(52.4)$ & $343(50.2)$ & $1135(0)$ & 0.465 \\
\hline Previous live births (mean (SD)) & $0.7(0.9)$ & $0.9(1.2)$ & $1069(66)$ & 0.063 \\
\hline
\end{tabular}




\begin{tabular}{|c|c|c|c|c|c|c|c|}
\hline & $\begin{array}{l}\text { Have MMR } \\
n(\%)\end{array}$ & $\begin{array}{l}\text { Delay MMR } \\
n(\%)\end{array}$ & $\begin{array}{l}\text { Single jabs } \\
n(\%)\end{array}$ & None $n(\%)$ & $\begin{array}{l}\text { Not sure/ } \\
\text { undecided } \\
n(\%)\end{array}$ & $\begin{array}{l}\text { Base } N=452 \\
n \text { (missing) }\end{array}$ & $\begin{array}{l}P \text { value for } \\
\text { difference }\end{array}$ \\
\hline All & $258(57.2)$ & $48(10.6)$ & 79 (17.5) & $53(11.8)$ & $13(2.9)$ & $452(1)$ & \\
\hline \multicolumn{8}{|l|}{$\begin{array}{l}\text { Maternal age at } \\
\text { birth of this child: }\end{array}$} \\
\hline$<18$ & $1(100)$ & $0(0)$ & $0(0)$ & $0(0)$ & $0(0)$ & $1(100)$ & \\
\hline $18-20$ & $4(80)$ & $0(0)$ & $0(0)$ & $0(0)$ & $1(20)$ & $5(100)$ & \\
\hline $21-24$ & $18(66.7)$ & $1(3.7)$ & $5(18.5)$ & $2(7.4)$ & $1(3.7)$ & $27(100)$ & \\
\hline $25-34$ & $143(61.4)$ & $17(7.3)$ & $45(19.3)$ & $23(9.9)$ & $5(2.2)$ & $233(100)$ & \\
\hline $35+$ & $84(49.1)$ & $27(15.8)$ & $29(17.0)$ & $25(14.6)$ & $6(3.5)$ & $171(100)$ & 0.119 \\
\hline \multicolumn{8}{|l|}{ First child: } \\
\hline Yes & $132(61.1)$ & $10(4.6)$ & $41(19.0)$ & $28(13.0)$ & $5(2.3)$ & & \\
\hline No & $126(53.6)$ & $38(16.2)$ & $38(16.2)$ & $25(10.6)$ & $8(3.4)$ & $451(1)$ & 0.002 \\
\hline \multicolumn{8}{|l|}{ Education: } \\
\hline Non-graduate & $134(62.3)$ & $19(8.8)$ & $34(15.8)$ & $20(9.3)$ & $8(3.7)$ & & \\
\hline Graduate & $124(52.5)$ & $29(12.3)$ & $45(19.1)$ & $33(14.0)$ & $5(2.1)$ & $451(1)$ & 0.14 \\
\hline
\end{tabular}

\begin{tabular}{|c|c|c|c|c|c|c|c|}
\hline & $\begin{array}{l}\text { Have MMR } \\
n(\%)\end{array}$ & $\begin{array}{l}\text { Delay MMR } \\
n(\%)\end{array}$ & $\begin{array}{l}\text { Single jabs } \\
n(\%)\end{array}$ & None $n(\%)$ & $\begin{array}{l}\text { Not sure/ } \\
\text { undecided } \\
n(\%)\end{array}$ & $\begin{array}{l}\text { Base } \\
N=452 n \\
\text { (missing) }\end{array}$ & $\begin{array}{l}P \text { value for } \\
\text { difference }\end{array}$ \\
\hline MMR recorded & 217 (96.9) & $6(2.7)$ & $1(0.5)$ & $0(0)$ & $0(0)$ & & \\
\hline $\begin{array}{l}\text { MMR not recorded, } \\
\text { but at least one other } \\
\text { vaccination given }\end{array}$ & $39(20.9)$ & 41 (21.9) & $78(41.7)$ & $16(8.6)$ & $13(7.0)$ & & \\
\hline $\begin{array}{l}\text { No vaccinations } \\
\text { recorded (Non- } \\
\text { vaccinator) }\end{array}$ & $2(5)$ & $1(2.5)$ & $0(0)$ & $37(92.5)$ & $0(0)$ & 451 (1) & $<0.001$ \\
\hline
\end{tabular}

the basis of self-reported 'intention-to-treat', which enabled us to capture decisions to delay MMR, or to give single vaccines, in this analysis. These selfreports were compared with data from the Child Health Dataset, and this comparison is reported in Table 3. This shows that only one child whose mother reported choosing not to give MMR or to give single jabs was recorded as having had MMR, while a few children whose mothers reported a decision to give MMR did not have MMR reported on the dataset.

In the analysis below, we define 'compliant' mothers as those who reported choosing to have MMR on time, and 'non-compliant' mothers as those choosing to delay MMR, not to vaccinate with MMR, to obtain single jabs, or who remained undecided.

\section{Use of complementary and conventional therapies}

Of the non-compliant mothers, $32.6 \%$ had consulted a homeopath, by contrast with $10.1 \%$ of compliers
$(P=0.001)$. No significant association was seen with consulting herbalists, acupuncturists, ayurvedic practitioners or kinesiologists. No association was seen with attendance at yoga for childbirth classes.

Rejection of the vitamin $\mathrm{K}$ injection routinely offered at birth was strongly associated with noncompliance. Only $19 / 63$ (30.2\%) of those who declined this injection went on to comply with MMR, by contrast with $221 / 363(60.9 \%)$ of those accepting it $(P<0.001)$.

We tested for differences between the various 'non-compliant' groups, in order to explore the potential for confounding by social factors, in particular non-vaccinator status (a multivariate analysis is therefore reported below in Table 7).

Among non-vaccinator mothers, as defined by the Child Health Database, 27/40 (67.5\%) were graduates, by contrast with $160 / 412$ (38.8\%) of those who had accepted some vaccinations, a difference which was not statistically significant $(P<0.822)$. 
Non-vaccinators were significantly more likely to have visited a homeopath $(27 / 40(67.5 \%)$ versus $62 /$ 412 (15.1\%), $P<0.001)$, and less likely to have accepted vitamin $\mathrm{K}((13 / 37$ (35.1\%) versus $351 /$ $390(90.0 \%), P<0.001$ ), while the child was no more likely to be their first.

Mothers who delayed MMR were no more likely to be graduates than others $(29 / 48(60.4 \%)$ versus $207 / 403(51.4 \%), P=0.24)$, while the child was less likely to be their first $(10 / 48(20.8 \%)$ versus $206 / 403$ (51.1\%), $P<0.001)$. They were no more likely to refuse vitamin $\mathrm{K}$, or to have visited a homeopath.

Mothers reporting a choice of single jabs were no more likely to be graduates $(45 / 79(57.0 \%)$ versus $191 / 372(51.3 \%), P=0.4$ ), while the child was no more likely to be their first, and they were no more or less likely to have visited a homeopath or declined vitamin $\mathrm{K}$.

\section{The process of decision-making and attitudes of healthcare professionals to decision- making}

Non-compliers reported earlier concerns about the MMR than others, with $58.0 \%$ reporting that it was an issue for them before the child's birth. These respondents were more concerned about family health issues related to the MMR, and less likely to see measles as a 'very' or 'quite' serious disease. Table 4 reports variables relating to the process of decision-making, which is notably reported to begin before birth in a majority of non-compliers. This association remained significant after controlling for number of previous children $(P<0.001)$.

We also explored non-compliers' perceptions of their health professionals' attitudes to their decisions. Of respondents answering the question, $60.0 \%$ of 193 non-compliers considered that their GP would disapprove of their choice, while $31.9 \%$ considered that he or she 'approved' or 'wouldn't mind'. By contrast, $45.5 \%$ considered that their health visitor would disapprove, with $46.8 \%$ believing she or he 'approved' or 'wouldn't mind'.

\section{General views on the MMR}

We explored a range of issues raised by parents in the course of ethnographic work, through presenting statements for agreement or disagreement. These are presented in Table 5. A third of noncompliant mothers reported knowing of children 'knocked back by MMR', and these mothers were more likely also to consider that not enough research had been done, or that they had insufficient information to make a decision.

Non-compliers were significantly more likely to report having attended public meetings on immunization $(23.4 \%$ versus $3.5 \%, P<0.001)$, and having read books on MMR (32.6\% versus $13.6 \%, P<0.001)$. Although they were no more or less likely to report seeing television/radio news $(67.4 \%$ versus $70.9 \%$, $P=0.6)$ or newspaper articles $(85.5 \%$ versus $80.6 \%$, $P=0.4)$, they more commonly reported having seen $\mathrm{TV} /$ radio documentaries $(66.8 \%$ versus $57.0 \%$, $P=0.048)$. There was a difference in the extent of finding information oneself on the internet $(53.4 \%$ for non-compliers, $31.4 \%$ compliers, $P<0.001$ ) but not in seeing information found by others on the internet $(20.7 \%$ non-compliers, $15.9 \%$ non-compliers, $P=0.4$ ).

\section{Child health and the MMR}

Of the mothers who reported that their child had had generally 'strong' health since birth, $96.3 \%$ were compliant and $92.4 \%$ were non-compliant, and there was no association between compliance and general health $(P=0.257)$. The questionnaire specifically explored aspects of health that were related to MMR in the ethnographic work, but there was no evidence of an association between compliance and the general health of the child, nor with the specific health problems eczema, allergies, eating problems and breathing problems. In total, $8.2 \%$ of non-compliant, but only $3.7 \%$ of compliant mothers reported worrying about the MMR because of their child's behaviour $(P=0.04)$.

Family health history was seen as relevant by many non-compliant mothers. In explaining more about this in free text, seven mothers mentioned a family history of Asperger's syndrome; two mentioned autism in the family; three mentioned experiences of autism onset following MMR in the family; 13 referred to relatives reacting badly to vaccines; ten referred to a family history of eczema, asthma or arthritis; five referred to a family history of irritable bowel; and several gave examples referring to neurological problems, auto-immune problems or ME (myalgic encephalomyelitis).

\section{Personal and social responsibilities, and the role of government}

Table 6 reports feelings of responsibility and attitudes to the state in relation to the MMR. It shows that an overwhelming majority both of compliant and non-compliant mothers take personal responsibility for the risks associated with MMR, 


\begin{tabular}{|c|c|c|c|c|}
\hline & Compliant $n(\%)$ & $\begin{array}{l}\text { Non-compliant } n \\
(\%)\end{array}$ & Base $\mathrm{N}$ & $\begin{array}{l}P \text { value for } \\
\text { difference }\end{array}$ \\
\hline \multicolumn{5}{|l|}{ Time MMR became a concern: } \\
\hline When MMR due & $78(31.2)$ & $18(10.2)$ & & \\
\hline When baby jabs due & $87(34.8)$ & $39(22.2)$ & & \\
\hline At time of birth & $18(7.2)$ & $14(8.0)$ & & \\
\hline Before birth & $61(24.4)$ & $102(58.0)$ & & \\
\hline Not sure & $6(2.4)$ & $3(1.2)$ & 426 & $<0.001$ \\
\hline \multicolumn{5}{|l|}{ Concern about family health in relation to } \\
\hline \multicolumn{5}{|l|}{ MMR: } \\
\hline Yes & $39(15.2)$ & $57(29.5)$ & & \\
\hline No & $215(83.7)$ & $133(68.9)$ & & \\
\hline Don’t know & $3(1.2)$ & $3(1.6)$ & 450 & 0.001 \\
\hline \multicolumn{5}{|l|}{ How serious is measles seen to be: } \\
\hline Very or quite & $241(93.4)$ & $155(80.3)$ & & \\
\hline Mild & $10(3.9)$ & $13(6.7)$ & & \\
\hline Don't know & $2(0.8)$ & $2(1.0)$ & & \\
\hline Other & $5(1.9)$ & $23(11.9)$ & 451 & $<0.001$ \\
\hline \multicolumn{5}{|l|}{ Who decides: } \\
\hline $\mathrm{Me}$ & $59(23.1)$ & $45(23.3)$ & & \\
\hline Me and partner & $195(76.2)$ & $148(76.7)$ & & \\
\hline Partner & $2(0.8)$ & $0(0)$ & 449 & 0.430 \\
\hline \multicolumn{5}{|l|}{ Who approves: } \\
\hline Health visitor approves & $232(91.3)$ & $18(9.7)$ & 440 & $<0.001$ \\
\hline GP approves & $239(94.5)$ & $19(10.1)$ & 441 & $<0.001$ \\
\hline \multicolumn{5}{|l|}{$\begin{array}{l}\text { Reasons for choice different from most } \\
\text { people you know: }\end{array}$} \\
\hline Yes & $33(12.8)$ & 77 (39.9) & 451 & $<0.001$ \\
\hline \multicolumn{5}{|l|}{$\begin{array}{l}\text { Do you feel certain you made the right } \\
\text { decision? }\end{array}$} \\
\hline Very certain, or fairly certain & $245(95.0)$ & $179(92.8)$ & & \\
\hline Not very certain & $13(5.0)$ & $14(7.3)$ & 451 & 0.022 \\
\hline \multicolumn{5}{|l|}{$\begin{array}{l}\text { Is there anything else you would have } \\
\text { wanted to know about MMR to help you } \\
\text { make a decision }\end{array}$} \\
\hline Yes & $170(69.4)$ & $83(44.2)$ & & \\
\hline No & $75(30.6)$ & $105(55.9)$ & 433 & $<0.001$ \\
\hline $\begin{array}{l}\text { I tend to avoid talking to my friends about } \\
\text { the } M M R \text { issue }\end{array}$ & $34(13.2)$ & $27(14.0)$ & 451 & 0.803 \\
\hline
\end{tabular}

${ }^{\mathrm{a} B y}$ contrast, $10(25 \%)$ of non-vaccinators strongly agreed, compared with $33(10.9 \%)$ of vaccinators, $P=0.01$.

whether they see those predominantly as the risks of preventable disease or side effects of immunisation. Parental choice was highly valued by nearly all parents, while herd immunity was unimportant to $40 \%$ of both compliant and non-compliant mothers. The right of health professionals to advise vaccination on the basis of the need for herd immunity was particularly questioned by non-compliers.

A large $71 \%$ of those who did not comply, but even $35 \%$ of those who did, strongly agreed that 'you can't trust the government over science'. Even higher proportions of mothers strongly ex- pressed suspicion of the influence of pharmaceutical companies over the MMR issue (52\% of those who complied, and $82 \%$ of those who did not). Over both these statements concerning trust, however, the difference between those who did and did not comply is statistically significant, with a higher proportion of those who did not comply expressing lack of trust.

Table 6 extends this consideration of how mothers relate to public issues involving science by exploring attitudes and practices around bovine spongiform encephalopathy (BSE) and genetically 
Table 5 Views on MMR.

$\begin{array}{llll}\begin{array}{l}\text { Compliant } n \\ (\%)\end{array} & \begin{array}{l}\text { Non- } \\ \text { compliant } n \\ (\%)\end{array} & \text { Base N } & \begin{array}{l}\text { P value for } \\ \text { difference }\end{array} \\ & & \\ \end{array}$

\section{General issues}

I know parents whose children have been

knocked back by the MMR

Strongly my view

Friends and family have had the MMR and

they were fine

Strongly my view

You can get bogged down in the detail,

too much research and you don't do anything

Strongly my view

There is no scientific proof that the MMR

vaccine causes autism or any other problems

Strongly my view

All the stuff you hear about the negative effects of the

MMR is media hype

Strongly my view

Not enough research has been done on the MMR

Strongly my view

I don't feel we have enough information to make

an informed decision

Immunity

There is a chance of serious side effects

from MMR if there is a weakness in that child

Strongly agree

Each child's immune system is different

Strongly agree

Single vaccines concern me but not as much as MMR

Strongly agree

The MMR is too much in one go

Strongly agree

It's better to get immunity naturally

Strongly agree

$\begin{array}{llll}13(5.1) & 56(29.8) & 444 & <0.001 \\ 215(85.0) & 109(57.4) & 443 & <0.001 \\ & & & \\ 101(41.1) & 46(25.0) & 430 & <0.001 \\ & & & \\ 162(64.0) & 30(16.0) & 441 & 0.001 \\ & & & \\ 92(36.1) & 14(7.4) & 445 & <0.001 \\ 83(32.8) & 159(83.7) & 443 & <0.001 \\ 59(23.4) & 119(62.6) & 442 & <0.001\end{array}$

$\begin{array}{llll}50(19.5) & 103(53.9) & 448 & <0.001 \\ 155(60.6) & 147(77.0) & 447 & <0.001 \\ 60(23.6) & 96(50.8) & 443 & <0.001 \\ 54(21.7) & 158(85.9) & 433 & <0.001 \\ 18(7.1) & 79(42.3) & 440 & <0.001\end{array}$

modified foods. A significantly higher proportion of those who did not comply with MMR claimed to have stopped eating beef because of BSE and this proportion might have been higher still but for the fact that $35 \%$ of non-compliers were vegetarian already. Of those who did not comply with MMR, $87 \%$ (and $62 \%$ of those who did) claimed that they checked food labels to see if they contain genetically modified organisms (GMOs) - again, a statistically significant difference, and a surprisingly high number in both groups.

\section{Predicting non-compliance?}

Given the variety of mothers' views on MMR, identifying characteristics that are both predictive of MMR uptake and relevant to the kind of immunisation information which individual parents are likely to find meaningful and convincing, is of interest to clinical and public health practitioners. Table 7 reports a multivariate analysis exploring the association between compliance with MMR and the objectively measurable variables graduate status, whether the child was a firstborn, maternal age, vitamin $\mathrm{K}$ injection at birth, consultation with a homeopath for the child and non-vaccinator status.

The data show that only use of a homeopath was independently associated with non-compliance. Vitamin $\mathrm{K}$ rejection (a less common decision) was no longer of significance after adjustment, possibly due to lack of statistical power, while there was no interaction between these two variables. 


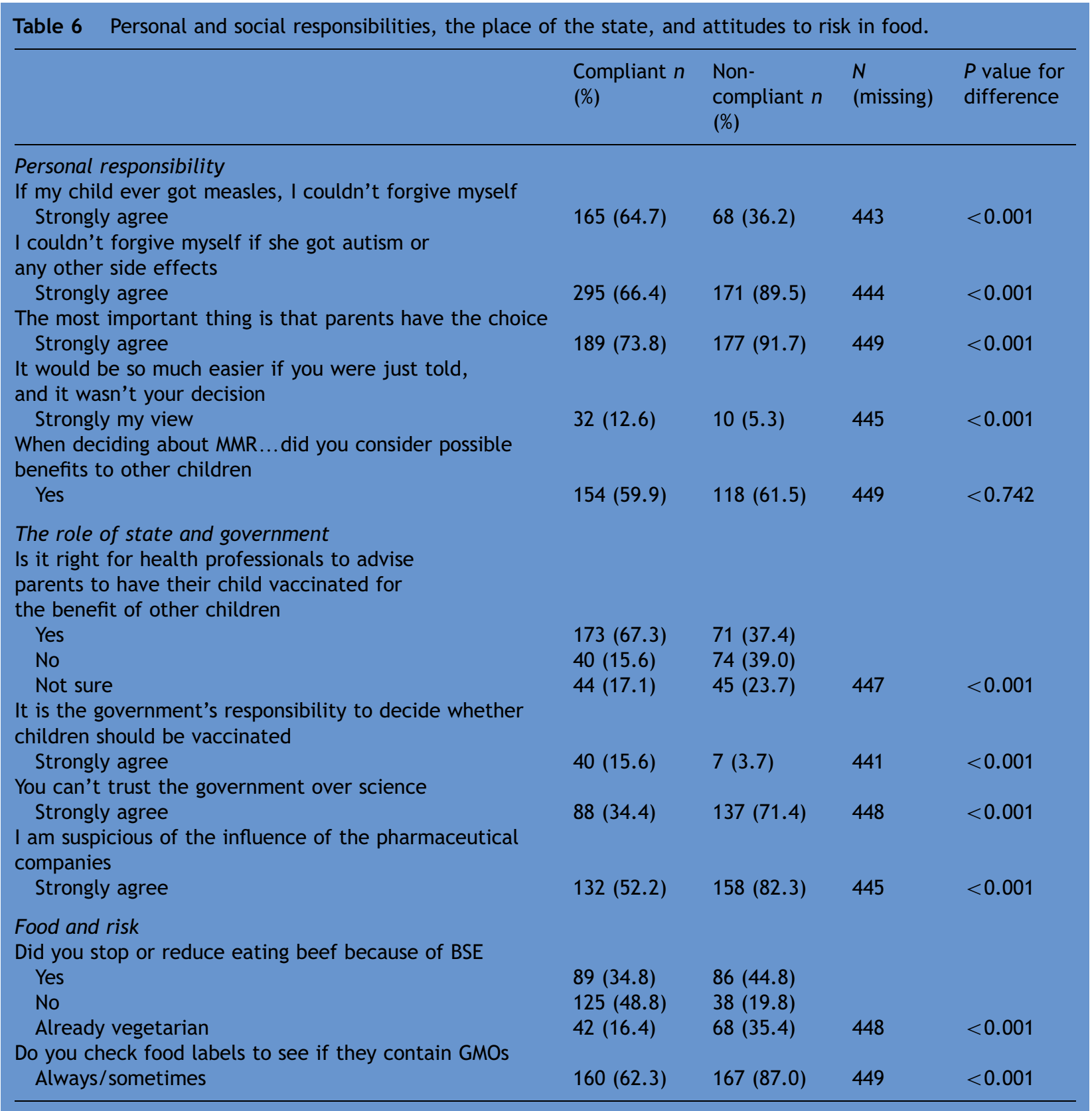

\section{Discussion}

\section{The relevance of lay concepts of child health and alternative healthcare}

An individualistic view of child health, manifest through family history as well as the health of the child, is experienced by mothers as highly relevant to their risk assessment for MMR. This survey confirms the importance of lay theories of immunity, focussed on the possibilities of immune overload in the context of individual 'weakness' in a child, which play a role in MMR decision-making, and puts it in the context of other health-seeking attitudes and behaviours. Homeopathy and public immunization debates appear to be influential in this context.

We were surprised by the lack of association between child health and compliance. It might suggest that children with allergic-type problems have closer early interactions with health services, with the effect of making them more likely to comply.

A view of the immune system as an individual characteristic, needing individualized healthcare, emerged in this survey as in the ethnography. Most 


\begin{tabular}{|c|c|c|c|c|}
\hline Variable & $\begin{array}{l}\% \\
\text { Reporting } \\
\text { compliance }\end{array}$ & $\begin{array}{l}\text { Crude OR } \\
(95 \% \mathrm{Cl}) \\
\text { for compliance }\end{array}$ & $\begin{array}{l}\text { Adjusted }^{\mathrm{a}} \mathrm{OR} \\
(95 \% \mathrm{Cl}) \\
\text { for compliance }\end{array}$ & $\begin{array}{l}\text { Number of } \\
\text { cases }^{b}\end{array}$ \\
\hline All & $53.9 \%$ & - & - & 413 \\
\hline Vitamin $\mathrm{K}$ injection at birth & & $P<0.0001$ & $P=0.159$ & \\
\hline Yes & $60.9 \%$ & 1 & 1 & 353 \\
\hline No & $30.0 \%$ & $0.28(0.15,0.50)$ & $0.60(0.30,1.22)$ & 60 \\
\hline Mother is a graduate $\mathrm{e}$ & & $P=0.006$ & $P=0.611$ & \\
\hline No & $63.6 \%$ & 1 & 1 & 195 \\
\hline Yes & $50.0 \%$ & $0.57(0.39,0.85)$ & $0.89(0.56,1.40)$ & 218 \\
\hline Used a homeopath & & $P<0.0001$ & $P=0.001$ & \\
\hline No & $63.0 \%$ & 1 & 1 & 332 \\
\hline Yes & $29.6 \%$ & $0.25(0.15,0.42)$ & $0.36(0.20,0.64)$ & 81 \\
\hline Mother's first child & & $P=0.165$ & $P=0.209$ & \\
\hline Yes & $60.0 \%$ & 1 & 1 & 195 \\
\hline No & $53.2 \%$ & $0.76(0.51,1.12)$ & $0.75(0.48,1.18)$ & 218 \\
\hline Mother's age $^{d}$ & & $P=0.0033$ & $P=0.0614$ & \\
\hline$<30$ & $73.9 \%$ & 1 & 1 & 69 \\
\hline $30-34$ & $57.8 \%$ & $0.48(0.26,0.91)$ & $0.51(0.25,1.02)$ & 147 \\
\hline $35-39$ & $51.7 \%$ & $0.38(0.20,0.71)$ & $0.46(0.23,0.93)$ & 149 \\
\hline $40+$ & $41.7 \%$ & $0.25(0.11,0.55)$ & $0.30(0.12,0.74)$ & 48 \\
\hline Vaccinated $^{c}$ & & $P<0.0001$ & $P=0.002$ & \\
\hline Yes & $61.1 \%$ & 1 & 1 & 380 \\
\hline No & $3.0 \%$ & $0.02(0.003,0.15)$ & $0.04(0.01,0.35)$ & 33 \\
\hline
\end{tabular}

mothers agreed that each child's immune system was different (although significantly more noncompliant mothers (77\%) strongly agreed with this, compared with $61 \%$ of those who complied).

What does differ, however, is how mothers evaluate how MMR plays into this, with $86 \%$ of mothers who did not comply strongly agreeing that 'the MMR is too much in one go' compared with only $22 \%$ of those who complied. Equally, more than half of the non-compliers agreed that there is a chance of serious side effects from MMR if there is a weakness in that child, compared to only $19 \%$ of those who complied. Of mothers who did not comply, $43 \%$ strongly agreed that it was better to 'get immunity naturally', compared with only $7 \%$ of those who complied.

The relevance of a belief that immunizations harm the immune system has been noted elsewhere, ${ }^{14,15}$ and our study quantifies a striking influence of homeopathy in this respect. Although our ethnographic work, along with other studies, points to the relevance of concerns about child health here, our mixed quantitative and qualitative methodology was able to show that this did not focus on specific illnesses, but on concepts of weakness and family health traits, which are less well captured by conventional concepts of health. The relevance of wider lay concepts of health, not captured in healthcare professionals' discourses on immunization, is likely to be of importance in addressing persistent concerns about the safety of $M M R,{ }^{16}$ which are not well explained in terms of 'rational' risk perception. ${ }^{17}$

\section{Determinants of uptake and 'single jabs'}

The uptake of measles immunization in Brighton may be up to $17 \%$ higher than measured by MMR uptake in the Child Health Database, if all those reporting that they chose single jabs in fact had these vaccines. This confirms findings by Wroe et al., and may have important implications for our capacity to predict the resurgence of measles. ${ }^{18}$ Our data also confirm their suggestion that many parents may be delaying MMR - a finding which has important implications for coverage estimates, and also for developing effective 'catch-up' policies. Records of the Medicines and Healthcare Regulatory Agency on the number of 
single dose measles vaccine doses authorized for import (not all of which will necessarily have been imported) show that that 103358 were authorized in 2003 and 91197 in 2004. ${ }^{19}$

By contrast with the suggestion of previous work that MMR anxiety is concentrated in more affluent groups, ${ }^{9,10}$ non-compliance was not associated in our study with graduate status, and concerns about MMR safety were reported in a wide range of compliers and non-compliers. This contradicts national parent opinion survey work by suggesting that that anxiety about MMR is a widespread phenomenon in all social classes, ${ }^{9}$ while confirming the findings of other researchers based in local health services. ${ }^{14,20-22}$

Interestingly, the total non-vaccinators in this study were a more educated group than other respondents, and more likely to use homeopaths and reject vitamin $\mathrm{K}$ than women choosing single jabs. Rather than an underprivileged group whose access to healthcare is marginal, these women are likely to have the economic advantages associated with graduate status. However, they may not be opinion leaders in the context of MMR, since (as reported in Table 3) they were less willing than others to discuss MMR with other mothers, in the social networks reported by our group and others. ${ }^{12,23}$

\section{Personal, social and governmental responsibility}

A major finding in the ethnographic work was that the MMR issue has become a focal point of social talk among mothers, which is consistent with a 'social contagion' model of immunization discourse. ${ }^{24} \mathrm{~A}$ question to probe this (Table 3 ) asked if mothers agreed that they tend to avoid talking to their friends about the MMR issue. As we expected, those who did and did not comply were very similar in this respect, with only $14 \%$ agreeing. However, it is notable that half of the non-compliers who did avoid talking about MMR were complete nonvaccinators (representing $25 \%$ of them), suggesting that total non-vaccination is a different social issue, a finding confirmed elsewhere ${ }^{22}$. These data are consistent with other work suggesting that social networks are important in the reinforcement of understanding and beliefs in relation to MMR. ${ }^{23}$

Parental choice emerged as an important value for both compliers and non-compliers, as is evidenced in a range of questions probing freedom of choice and the role of government in Table 5. Very few mothers, whether or not they complied, strongly agreed that it would be easier if the decision were made for them.

A substantial proportion of all mothers, but more non-compliers, distrusted the government over science. This, together with suspicions of the influence of pharmaceutical companies, suggests a widespread perception of bias in official statements of MMR safety.

A strong theme that emerged in the ethnography was a pronounced sense of personal responsibility, and assumption of personal blame, for any harm that might come to a child either through disease or through vaccination adverse effects. The survey responses in Table 5 confirm this sense of personal responsibility, though unsurprisingly those who complied expressed their personal responsibility more in worry about measles that about possible MMR side effects.

However, the assuming of responsibility appears to relate mainly to a mother's own child. Thistaken with the high sense of personal responsibility evident in mothers' responses - suggests that the MMR issue has become so important that personal parenting concerns are paramount, leaving less space for wider social considerations. Nevertheless a much higher proportion $(67 \%$ of those who complied, and $38 \%$ of those who did not) felt that it was right for health professionals to push this social message.

The high prevalence of vegetarianism, concerns about BSE and about GMOs suggest that while many mothers across the vaccination spectrum may be taking a precautionary approach around these other issues of scientific uncertainty, there is for many mothers a close connection between health behaviours relating to food and those relating to vaccination.

\section{Limitations of this study}

This study focuses on a single urban locality, which has particularly low rates of MMR uptake, and in offering an 'alternative' lifestyle may not be representative of the UK as a whole. However, the social factors causing low uptake in Brighton may well be similar in kind to those operating elsewhere, even if their distribution is different. A response rate of $39.8 \%$, though lower than desirable, is higher than average for postal surveys of the public, and is similar to the effective participation rate in other published survey work. ${ }^{18}$ It is likely to be an underestimate of the true response rate (especially for total non-vaccinators), due to high rates of migration locally, and in young families particularly, as well as 'ghost' 
patients. A smaller questionnaire study of infant immunization estimates the 'ghost' rate at $14.7 \%,{ }^{16}$ a finding which if applied to our data would give a response rate of $46.7 \%$. Due to lack of resources, we were not able to verify the true response rate in Brighton.

The single mailing to non-vaccinators, in contrast to the follow-up questionnaire sent to others, is a potential source of bias and is likely to account for the lower response rate in this group. This would be of importance for a detailed study of this group, but as the main focus of this study was MMR noncompliance, and this group was relatively small, this bias is likely to have had minimal impact on our comparisons between non-compliers and others.

\section{Relevance of this study for further work and for health promotion policy}

This study has important implications for health promotion in general, and the promotion of immunization in particular. Non-compliant mothers appear to be well-informed individuals who have considerable interest in health-related issues, as manifest through food choices, and an early onset of interest in the MMR issue. Health promotion theory and practice tends to encourage awareness and empowerment among disadvantaged and marginalized groups. In the case of MMR, health awareness appears (at least for some individuals) to be associated with reduced acceptance of MMR and with acceptance of lay theories of immune function and health. This finding is in keeping with data showing that the provision of additional detailed information does not improve MMR uptake in children not yet immunized at 21 months. ${ }^{25}$

The emergence of homeopathy and vitamin $K$ (the latter of borderline significance, probably due to limited power) as predictors of non-compliance is both a striking finding, and an opportunity. Previous research has shown that most homeopaths do not recommend MMR vaccination. ${ }^{26,27}$ However, there has been less publicity over concerns about a possible link between vitamin $\mathrm{K}$ and childhood cancer $^{28}$ than about MMR. We show in this study that views of immunity associated with homeopathic conceptions of health disease are widespread, while consultation with a homeopath was itself strongly associated with non-compliance. This suggests that health promotion materials must take into account widely disseminated views on immunity that are very different from the immunological theories on which immunization practice and policy are based. Our finding that rejection of vitamin $\mathrm{K}$ and use of homeopathy for a child both strongly predict MMR non-compliance provides an opportunity to identify a 'community' defined by health beliefs for developing such work.

This presents a paradox for evidence-based health promotion. In order to convince those most likely to become MMR non-compliers of its safety, there is a need to engage with, and share the discourse of, concepts of immunity which western science and medicine explicitly reject. The public health community will need to consider whether evidence-based practice needs to presume shared paradigms of the nature and mechanisms of healthcare interventions, or whether it is prepared to develop 'propaganda' which promotes immunization through concepts of health it cannot share.

The challenge of developing immunization educational materials for a public who have a developed, dissonant scientific view is both a practical and an ideological challenge, whose implications reach beyond the MMR debate into ethical questions of what constitutes informed consent to public health interventions in a diverse society.

\section{Acknowledgements}

We would like to thank our advisory group (Graham Bickler, Mark Jones, Martina Pickin, Tom Scanlon, Isabella Thomas and Joanne Yarwood) for helpful comments. We would also like to acknowledge practical support from Surrey and Sussex Health Protection Agency, South Downs NHS Health Trust, and Brighton and Hove City Primary Care Trust). The study was funded by the Economic and Social Research Council. Peter Trail provided assistance with data management and Hannah Evans assisted in the statistical analyses.

The authors declare that they have no competing interests.

\section{References}

1. Wakefield AJ, Harvey P, Linnell J. MMR—responding to retraction. Lancet 2004;363:1327-8.

2. Horton R. The lessons of MMR. Lancet 2004;363:747-9.

3. Horton R, editor. A statement by the editors of The Lancet. Lancet 2004;363:820-1.

4. Murch S. A statement by $\mathrm{Dr}$ Simon Murch. Allegations concerning our 1998 study. Lancet 2004;363:821-2.

5. Wakefield A. A statement by Dr Andrew Wakefield. Lancet 2004;363:823-4.

6. Smeeth L, Cook C, Fombonne E, Heavey L, Rodrigues LC, Smith PG, et al. MMR vaccination and pervasive developmental disorders: a case-control study. Lancet 2004;364: 963-9.

7. Taylor B, Miller E, Farrington CP, Petropoulos MC, FavotMayaud I, Li J, et al. Autism and measles, mumps, and 
rubella vaccine: no epidemiological evidence for a causal association. Lancet 1999;353:2026-9.

8. Honda $H$, Shimizu $Y$, Rutter M. No effect of MMR withdrawal on the incidence of autism: a total population study. J Child Psychol Psychiatry 2005;46:572-9.

9. Ramsay ME, Yarwood J, Lewis D, Campbell H, White JM. Parental confidence in measles, mumps and rubella vaccine: evidence from vaccine coverage and attitudinal surveys. $\mathrm{Br} \mathrm{J}$ Gen Pract 2002;52:912-6.

10. Middleton E, Baker D. Comparison of social distribution of immunisation with measles, mumps, and rubella vaccine, England, 1991-2001. BMJ 2003;326:854.

11. Roberts KA, Dixon-Woods M, Fitzpatrick R, Abrams KR, Jones DR. Factors affecting uptake of childhood immunisation: a Bayesian synthesis of qualitative and quantitative evidence. Lancet 2002;360:1596-9.

12. Poltorak M, Leach M, Fairhead J, Cassell J. 'MMR talk' and vaccination choices: an ethnographic study in Brighton. Soc Sci Med 2005;61:709-19.

13. Department of Health. NHS Immunisation Statistics 2003-04. Department of Health; 2004.

14. Flynn M, Ogden J. Predicting uptake of MMR vaccination: a prospective questionnaire study. Br J Gen Pract 2004;54: 526-30.

15. Offit PA, Quarles J, Gerber MA, Hackett CJ, Marcuse EK, Kollman TR, et al. Addressing parents' concerns: do multiple vaccines overwhelm or weaken the infant's immune system? Pediatrics 2002;109:124-9.

16. Smailbegovic MS, Laing GJ, Bedford $H$. Why do parents decide against immunization? The effect of health beliefs and health professionals. Child Care Health Dev 2003;29:303-11.

17. Hobson-West P. Understanding vaccination resistance: moving beyond risk. Health Risk Soc 2003;5:273-83.
18. Wroe AL, Bhan A, Salkovskis P, Bedford H. Feeling bad about immunising our children. Vaccine 2005;23:1428-33.

19. Response to enquiry under Freedom of Information Act. Authorisations for imports of measles vaccine, 2005 (personal communication).

20. Evans M, Stoddart H, Condon L, Freeman E, Grizzell M, Mullen R. Parents' perspectives on the MMR immunisation: a focus group study. Br J Gen Pract 2001;51:904-10.

21. Casiday R, Cresswell T, Wilson D, Panter-Brick C. A survey of UK parental attitudes to the MMR vaccine and trust in medical authority. vaccine 2006;24:177-84.

22. Samad L, Tate AR, Dezateux C, Peckham C, Butler N, Bedford M. Differences in risk factors for partial and no immunisation in the first year of life: prospective cohort study. BMJ 2006;332:1312-3.

23. Petts J, Niemeyer S. Health risk communication and amplification: learning from the MMR vaccination controversy. Health Risk Soc 2004;6:7-23.

24. Scherer CW, Cho HC. A social network contagion theory of risk perception. Risk Anal 2003;23:261-7.

25. Mason BW, Donnelly PD. Impact of a local newspaper campaign on the uptake of the measles mumps and rubella vaccine. J Epidemiol Community Health 2000;54: 473-4.

26. Schmidt K, Ernst E, Andrews. Aspects of MMR. Survey shows that some homoeopaths and chiropractors advise against MMR. Issue Series Title: BMJ 2002;325:597.

27. Schmidt K, Ernst E. MMR vaccination advice over the Internet. Vaccine 2003;21:1044-7.

28. Fear NT, Roman E, Ansell P, Simpson J, Day N, Eden OB, et al. Vitamin $\mathrm{K}$ and childhood cancer: a report from the United Kingdom Childhood Cancer Study. Br J Cancer 2003;89: 1228-31.

Available online at www.sciencedirect.com

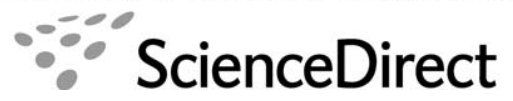

